\title{
Application of soft computing technique in the modelling and prediction of gold and silver rates
}

\author{
M. Dhiyanji ${ }^{1,}{ }^{*}$, K. Sundaravadivu ${ }^{2}$ \\ ${ }^{1}$ Department of Commerce, Madras University, Chennai, Tamilnadu, India \\ ${ }^{2}$ Department of Electronics and Instrumentation Engineering, Anna University, Chennai, India
}

\author{
Index Terms \\ Gold rate \\ Silver Rate \\ Box Jenkins Model \\ ARIMA Model \\ Kalman Filter PSO
}

Received: 7 May 2016

Accepted: 28 May 2016

Published: 12 August 2016

\begin{abstract}
Over the past few years, the modeling approach is widely used to discover the complex and dynamic relationship between various profitable variables. This paper focuses on the modeling of gold and silver rates concerning a certain period and predicting the gold and silver rates. In this paper, with the assistance of the Particle Swarm Optimization (PSO) algorithm, the BOX JENKINS and the Auto-Regressive Integrated Moving Average(ARIMA) models are developed for the considered economic variables. A comparative study is also presented to assure the model's accuracy. Following that, the PSO-based KALMAN FILTER DESIGN approach is implemented on the gold and silver rates to forecast market prices. In today's unpredictable world, investors believe that gold can act as a hedge against unexpected disasters, both natural and economic. Therefore forecasting the price of gold has been of the highest interest. The major advantage of the proposed PSO-based modeling and prediction approach is that it is a fully automated method which results in higher flexibility and greater accuracy. This study also confirms that the PSO-based ARIMA model yields a better result than the PSO-based BOX JENKINS model. The proposed PSO-based KALMAN FILTER approach also provides better predictions.
\end{abstract}

(C) 2016 The Author(s). Published by TAF Publishing.

\section{INTRODUCTION}

Gold and silver are the chief commodities in the world, whose value plays most noteworthy role in economic and financial systems. In particular, the values of gold and other assets in the nation are often closely correlated [1-3]. From an investment point of view, there are supplementary motivations for depositors in gold and silver, since both the metals are widely used in the jewellery markets. Due to the use of gold and silver in

\footnotetext{
${ }^{*}$ Corresponding author: M. Dhiyanji

E-mail:dhiyanji96@gmail.com
}

industrial fields, such as medical, precious electronic good fabrication, and food preparation, the demand for gold and silver has been increasing day by day.

From the past, present and future, gold is considered as one of the most important commodities in the world, because it retains its value during unexpected natural, political and economical disasters. From the literature, it can also be noted that, there is a correlation between the change in oil price and gold rate.

Hence, in order to support the investment towards the gold and silver, accurate forecasting of gold and silver price is necessary to predict the future trends in the market. This 
prediction will assist the stakeholders to accomplish the necessary deeds in order to avoid or reduce risks, which may lead to financial losses or even bankruptcy $[4,5]$.

The prediction analysis performed in this work is closely related to previous works existing in the literature. It helps to learn the past relationship between gold and silver prices and their future prediction. In this work, the gold and silver rates are analyzed for a period of 17 months (January 2015 to May 2016) [6].

Initially, the prices are modelled using the well-known modelling procedures, such as Box-Jenkins (B-J) model and Auto-Regressive Integrated Moving Average (ARIMA) model [7-9]. The accuracy of the traditional procedure mainly depends on the adopted method and sometimes it is very difficult to attain the optimal result due to its practical constraints. From the recent literature, it can also be noted that, heuristic algorithm based approaches are widely adopted to solve a variety of optimization problems [10-13]. In this work, we proposed Particle Swarm Optimization (PSO) assisted by ARIMA and B-J modelling approaches to model the gold and silver prices. In this work, a three dimensional search is used to assign the three non-negative integers of the ARIMA model. The result is then compared with the result obtained with the B-J model. The superiority of the PSO-based ARIMA model over PSO-based B-J model is confirmed with a comparative analysis of error parameters, such as Root Mean Square Error (RMSE). Mean Absolute Error (MAE) and Mean Absolute Percentage Error(MAPE) [7]. Finally, the Kalman filter [14-16] design approach is implemented for the considered gold and silver data set to predict the market price.

All the simulations are carried out using the Matlab software and results show that the proposed approaches offer a better result in modelling and prediction of gold and silver rates.

This paper is organised as follows: section 2 describes the related works existing in the literature. Introduction to PSO and its application towards B-J, ARIMA and Kalman filter are discussed in section 3. Results of the present work are presented in section 4 and its conclusion is discussed in section 5 .

\section{RELATED PREVIOUS WORKS}

Li proposed a Wavelet Neural Network (WNN) model designed with the Artificial Bee Colony (ABC) algorithm to forecast the gold rate [1]. This procedure helped to achieve the better result with faster algorithm convergence.
Similar approach was proposed by Mombeini and YazdaniChamzini using the Artificial Neural Network (ANN) [2]. In their work, the ANN is used to create a nonlinear model based on the gold price. A detailed relation-based examination between the gold price, oil price, exchange rate and stock market returns was performed by Sujit and Kumar [3]. This work proved that, the gold rate affects the related parameters. A detailed study about the global gold market was presented by Shafiee and Topal [4]. Recently, Chandar et al., presented ANN-based gold price forecasting using the well-known gold database existing in the literature [5].

Khan discussed about the gold price forecasting based on the Box Jenkins model [7]. In this work, the forecasting accuracy is computed with the help of RMSE, MAE and MAPE. Abdullah presented ARIMA-based gold price forecasting methodology [8]. A detailed description about the linear and non-linear forecasting approaches is existing in the literature [9]. A detailed description about the PSO algorithm and its various applications can be found in literature [10-13].

\section{METHODOLOGY}

Particle Swarm Optimization (PSO) algorithm, developed by Kennedy and Eberhart [10], is a global optimization technique developed with the inspiration of natural activities in flock of birds and school of fish, and is generally applied in a range of engineering problems due to its high computational competence [11-13].

In PSO, a group of artificial birds is initialized with arbitrary location $X_{i}$ and velocities $V_{i}$. At early searching phase, each bird in the swarm is scattered erratically all over the dimensional search space $D$. With the supervision of the Objective Function (OF), own flying experience and their companions flying experience, each particle in the swarm dynamically adjusts its flying position and velocity. During the optimization search, each particle remembers its best position attained so far (i.e.

pbest- $\left(P_{i, n}^{t}\right)$, and also finds the global best position value attained by any other particle in the population (i.e. gbest$\left(G_{i, n}^{t}\right)$ ). At iteration $t$, each particle ${ }^{i}$ has its position defined by $X_{i . n}^{t}=\left[X_{i, 1}, X_{i, 2}, \ldots, X_{i, D}\right]$ and velocity defined as $\mathrm{V}_{\mathrm{i}, \mathrm{n}}^{\mathrm{t}}=\left[\mathrm{V}_{\mathrm{i}, 1}, \mathrm{~V}_{\mathrm{i}, 2}, \ldots, \mathrm{V}_{\mathrm{i}, \mathrm{D}}\right]$ in search space $D$. 
Velocity and position of each particle in the next iteration can be calculated as:

$$
\left.\mathrm{V}_{\mathrm{i}, \mathrm{n}}^{\mathrm{t}+1}=\Psi * \mid \mathrm{V}_{\mathrm{i}, \mathrm{n}}^{\mathrm{t}}+\mathrm{C}_{1} * \mathrm{R}_{1} *\left(\mathrm{P}_{\mathrm{i}, \mathrm{n}}^{\mathrm{t}}-\mathrm{X}_{\mathrm{i}, \mathrm{n}}^{\mathrm{t}}\right)+\mathrm{C}_{2} * \mathrm{R}_{2} *\left(\mathrm{G}_{\mathrm{i}, \mathrm{n}}^{\mathrm{t}}-\mathrm{X}_{\mathrm{i}, \mathrm{n}}^{\mathrm{t}}\right)\right\rfloor
$$

where, $\mathrm{i}=1,2, \ldots, N$ and $\mathrm{n}=1,2, \ldots, D$

$$
X_{i, n}^{t+1}=\left\{\begin{array}{c}
X_{i, n}^{t}+V_{i, n}^{t+1} \text { if } X_{\min i, n} \leq X_{i}^{t+1} \leq X_{\max i, n} \\
X_{\min i, n} \text { if } X_{i, n}^{t+1}<X_{\min i, n} \\
X_{\max i, n} \text { if } X_{i, n}^{t+1}>X_{\max i, n}
\end{array}\right.
$$

where $D$ is the search dimension (number of variables to be optimized), $t$ is the iteration number, $N$ is the total number of the swarms, $X_{i, n}^{t+1}$ is the updated position value, $V_{i, n}^{t+1}$ is the updated velocity value, $R_{1}$ and $R_{2}$ are the random numbers in the range [0,1], $X_{\min }$ is the initial position of a swarm in the search space and $X_{\max }$ is the final position of the swarm in the search space.

In Eqn. (1), constriction factor $\Psi$ is responsible for updating the velocity operator of the algorithm which decides the convergence and optimization accuracy. The constriction factor can be assigned using the following equation:

$$
\Psi=\frac{2}{\left|2-\varphi-\sqrt{\varphi^{2}-4 \varphi}\right|}
$$

$$
\text { Where } \varphi=C_{1}+C_{2}, \varphi>4
$$

Acceleration constant $C_{1}$ (chosen as 1.8) pulls each particle towards local best position and constant $C_{2}$ (chosen as 2.4) called social parameter pulls the particle towards global best position. $R_{1}$ and $R_{2}$ are known as random numbers in the range 0-1 [11]. In this work, the total numbers of swarms are chosen as 25 and the total iteration value $(t)$ is chosen as 5000 .

\section{IMPLEMENTATION}

Implementation of the proposed methodology is depicted in Fig.1. In this, the PSO algorithm arbitrarily adjusts the ARIMA/B-J/Kalman filter parameters, until the error (Error $=$ Actual price - predicted price) between the modelled/predicted value and the original dataset is less.

In this, the dimension of the PSO search is assigned based on the implemented system identification procedure.

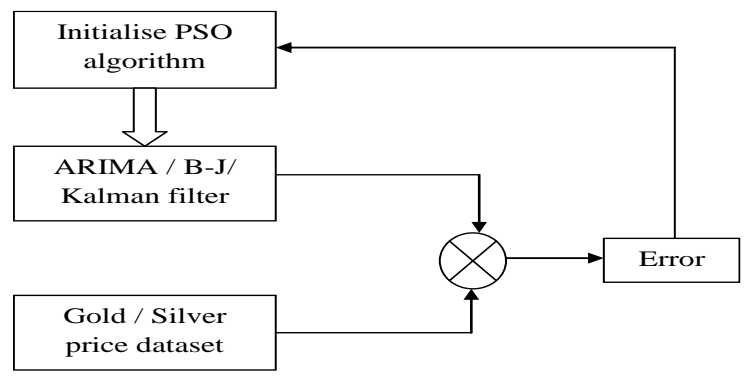

Fig.1. PSO Algorithm implementation

Execution of the PSO assisted approach is as follows:

Step 1: Plot the data (gold/silver rate) and consider it as the actual output $y$.

Step 2: Initialize the PSO algorithm with chosen algorithm parameters (swarm size $=25$, iteration number $=5000), R_{1}=R_{2}$ random variables in the range $[0,1]$, local search co-efficient $C_{1}=1.8$, Global search co-efficient $C_{2}=$ 2.4 and dimension of search $D$ (based on the system to be designed)

Step 3: Consider the stopping criteria as the error $(\varepsilon)=y$ $\sim \mathrm{y}^{*}$

Is $f_{\min }$ [system parameter] $=\mathrm{y} \sim \mathrm{y}^{*}$

Step 4: Arbitrarily adjust the system (B-J/ARIMA/KF) parameters, till $f_{\min }$ is reached.

Step 5: If $f_{\min }$ is achieved, stop the search and display the results.

\section{A. Box-Jenkins}

Box-Jenkins (B-J) approach is extensively considered for identification of the system from the experimental data [7, 9].

B-J model discussed by Selvanathan and Selvanathan [17] is considered in this paper:

The basic data considered to implement the B-J model is as follows:

$P_{U S D} t=\alpha+\beta+P_{U S D} \mathrm{t}-1+U_{t}$ for $\mathrm{t}=2, \ldots \ldots . .$.

where $\alpha$ and $\beta$ are arbitrary constants in the range [0,1], $U_{t}$ is the white noise, $T$ is the sample size (day or week), $P_{U S D}$ - 1 is the current price and PUSD $t$ is the new price.

In the proposed work, the following mathematical relation is considered while implementing the B-J approach to model the gold/silver price.In general, the Box and Jenkins (B-J) model is a modified form of the basic ARIMA model:

The general B-J model for the given data ' $y$ ' can be expressed as: 


$$
y^{*}=\Phi y_{\mathrm{t}-1}+\Phi \mathrm{y}_{\mathrm{t}-2}+\ldots+\Phi \mathrm{y}_{\mathrm{t}-\mathrm{p}}+\Theta \varepsilon_{\mathrm{t}-1}+\Theta \varepsilon_{\mathrm{t}-2}+\ldots+\Theta \varepsilon_{\mathrm{t}-\mathrm{q}}
$$

where, $t$ is the data instances, $\mathrm{y}$ is the considered gold/silver data for modelling, $\mathrm{y}^{*}$ is the computed data for $t$ instants, $\varepsilon$ is the error between the actual output (y) and the model output $\left(y^{*}\right), p$ and $q$ are the orders of auto regressive and moving average polynomials respectively( automatically generated based on the samples of y).

In Eqn. (4), the parameters $\Phi$ and $\theta$ are the basic B-J parameters. In the proposed work, the PSO algorithm adjusts the values of $\Phi$ and $\theta$ for the gold/silver rate in such a way that, the error between $y$ and $y^{*}$ is minimum for all the sampling instances.

\section{B. ARIMA}

Auto Regressive Integrated Moving Average (ARIMA) model is widely used for forecasts[8]. It has three parts which are Auto Regression (AR), Integration (I) and Moving Average (MA).

Generally, ARIMA is classified as the seasonal and non-seasonal models. The general seasonal model is indicated as ARIMA (pdq) (PDQ), where $p, d$ and $q$ refer to the orders of the non-seasonal model and P, D and Q refer to the orders of the seasonal model respectively.

In this work, a seasonal model is considered and the PSO based search offered the following values;

- for gold rate:

ARIMA (pdq) (PDQ)=ARIMA ( $\left.\begin{array}{lll}2 & 1 & 1\end{array}\right)\left(\begin{array}{lll}1 & 0 & 1\end{array}\right)$ with the following values:

$\operatorname{ar} 1=\{0.8715,0.1712\}$, ma1 $=\{-0.4726,0.1826\}$, and sma1 $=\{-0.6287,0.2816\}$,

- for silver rate:

ARIMA (pdq) (PDQ)=ARIMA ( $\left(\begin{array}{lll}1 & 1 & 1\end{array}\right)\left(\begin{array}{lll}1 & 0 & 1\end{array}\right)$ with the following values:

$\operatorname{ar} 1=\{0.6729,0.1664\}$, ma $1=\{-0.5026,0.1775\}$, and sma1 $=\{-0.6027,0.2841\}$

where ar1 is the auto regressive co-efficient, ma1 is the co-efficient $\theta$ at that instant and sma 1 is $\Phi$. In this $\theta$ and $\Phi$ are basic ARIMA parameters.

\section{Kalman Filter}

Kalman Filter (KF) and its recent advancements are widely used to track the data in order to predict the data value for the upcoming instants. The KF works based on linear dynamic systems discretized in the time domain. They are modelled on a Markov chain built on linear operators perturbed by errors.

The basic equation of the KF is given below;

$$
\begin{aligned}
& X_{k}=A_{k} X_{k-1}+B_{k} U_{k}+W_{k} \\
& Y_{k}=C X_{k-1}
\end{aligned}
$$

where $A_{k}$ is the state-transition model, $X_{k-1}$ is the past input value, $B_{k}$ is the control-input model, $U_{k}$ is the control vector, $Y_{k}$ is the output value, $W_{k}$ is the process noise and $X_{k}$ is the predicted value. In this work, A, B and C are the matrix values and the noise term $W_{k}=0$.

In this work, the Kalman filter discussed in [16] is adopted for the gold and silver rate prediction for 40-week data chosen from Jan 2015 to May 2016. In the proposed work, the PSO algorithm is adopted to find the kalmf parameters, which provide the minimal error.A detailed explanation about the Kalman filter can be found in literature [15] and its PSO implementation can be found in literature [13-14-16].

\section{RESULTS AND DISCUSSION}

This section presents the simulation results obtained from the proposed work. All the results shown here are obtained using the Matlab software.The gold/silver rate database is created using the data from Jan 2015 to May 2016 existing in literature [6]. From this database, it is observed that the gold rate on 02 Jan 2015 is 1188.47 USD and on 02 May 2016 is 1291.40 USD. Similarly, silver rate on 02 Jan 2015 is 15.733 USD and 02 May 2016 is 17.535 USD. This data is considered with a sampling rate $T=$ three days.

The proposed modelling technique is implemented as discussed in section 3.1. Initially the gold/silver rate data plotted with a sampling rate of three days for the considered database. Then, the PSO assisted B-J and ARIMA modelling procedures are implemented. Fig.2 shows the ARIMA and B-J results on the considered dataset. In this result, it can be noted that, the ARIMA model closely tracks the dataset compared with the B-J model. This data is plotted based on the gold rate in USD with respect to the month.

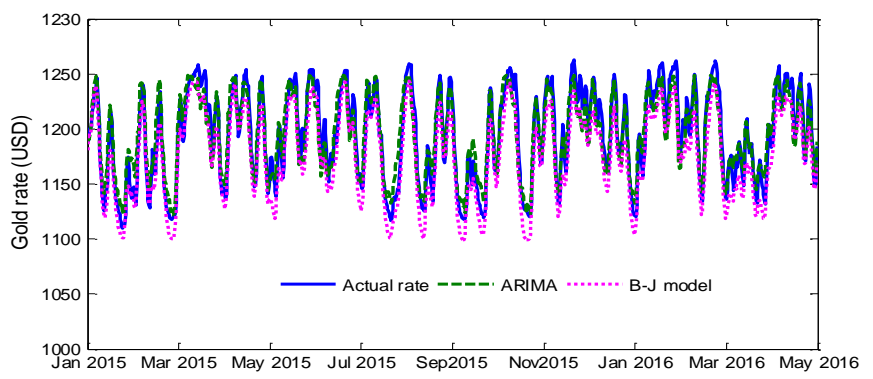

Fig. 2. Gold rate prediction with ARIMA and B-J model 


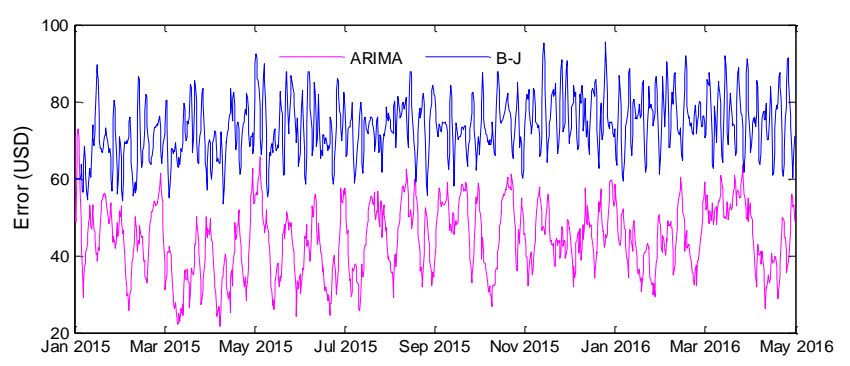

Fig. 3. Model error of the B-J and ARIMA for the gold rate

Fig. 3 shows the modelling error obtained in this study for the gold rate dataset. The error value is normally chosen as the variation of the price in USD. From this result, it can be noted that, the error offered by the B-J model is higher when compared with the ARIMA model. This study confirms that the model developed with the ARIMA is better in tracking the gold rate compared with the B-J.

Later, similar procedure is implemented for the silver rate and the obtained result is depicted in Fig. 4. From this figure, it can be noted that the ARIMA model-based tracking is better when compared with the B-J model.

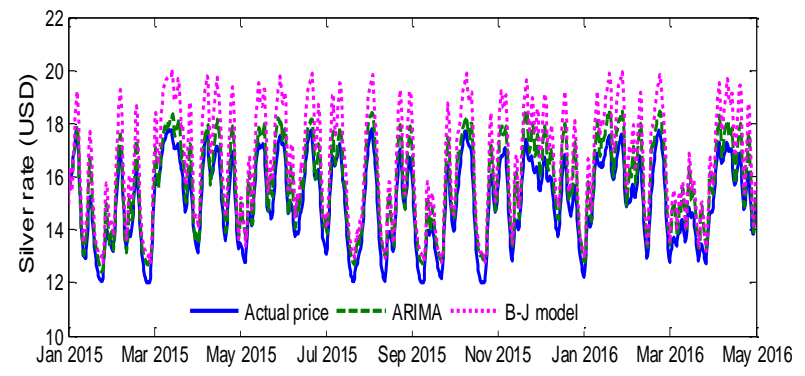

Fig. 4. Silver rate prediction

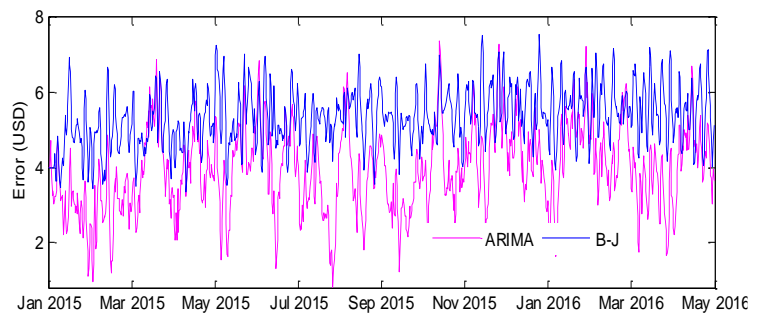

Fig.5. Model error of the B-J and ARIMA for the silver rate

Fig. 5 shows the error (in USD) obtained for the B-J model and the ARIMA. From this image, it can be noted that the mean error provided by the ARIMA model (20.85\%) is lesser compared with the B-J (23.26) The model accuracy can be improved by considering the most related constraints such as the demand, oil price, stock value, etc.
TABLE 1

ERROR MEASURES OBTAINED WITH B-J AND ARIMA FROM THE GOLD AND SILVER RATE MODEL

\begin{tabular}{llccr}
\hline \hline \multirow{2}{*}{ Error } & \multicolumn{3}{c}{ Gold rate model } & \multicolumn{2}{c}{ Silver rate model } \\
\cline { 2 - 5 } & \multicolumn{1}{c}{ B-J } & ARIMA & B-J & ARIMA \\
RMSE & 21.2379 & 20.0474 & 23.8432 & 20.1195 \\
MAE & 14.2874 & 14.1937 & 16.2298 & 16.1038 \\
MAPE & 1.0836 & 1.0330 & 1.03734 & 1.05493 \\
\hline \hline
\end{tabular}

From this table, it can be observed that the error offered by the ARIMA is lesser when compared with B-J.

Finally, the proposed method is implemented to design the Kalman filter for the considered dataset. Here Kalman filter is designed to predict the values from one-step prediction to ten-step prediction. Fig. 6 and 7 show the ten-step prediction for the 40-week data chosen in the middle of Jan 2015 to May 2016 from literature [6] with a sampling period of three days.

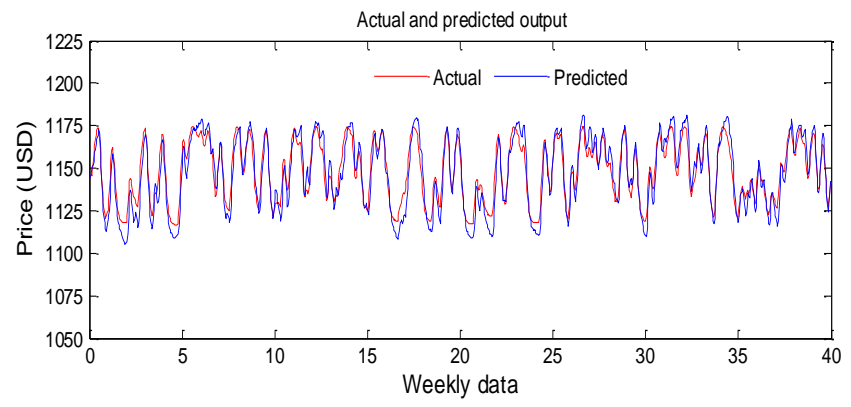

Fig. 6. Kalman filter based gold rate prediction

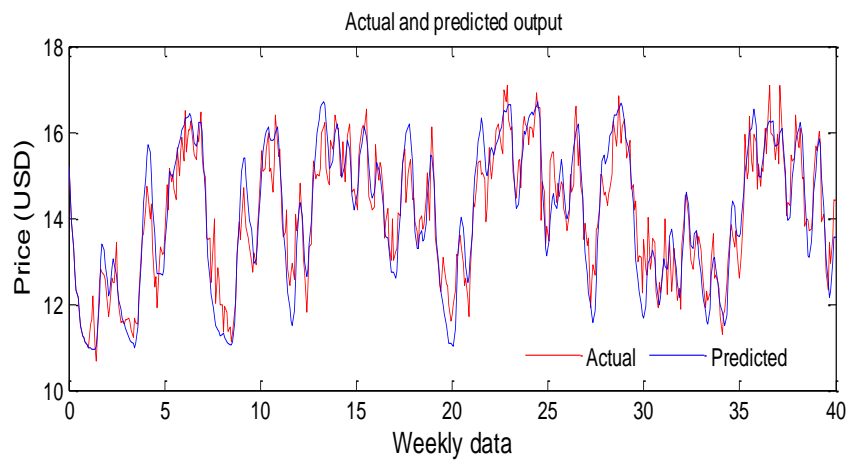

Fig. 7. Kalman filter based silver rate prediction

Table 2 and Fig. 8 depicts the predicted value of the gold/silver rate and its corresponding error values ( difference between actual and predicted value) from 1 step prediction $\left(X_{k}\right)$ to 10 step prediction $\left(X_{k+9}\right)$ respectively. From this, it can be noted that, the prediction accuracy is 
good at 1step and it decreases as the steps increase.

TABLE 2

KALMAN FILTER BASED PREDICTIONS FOR GOLD/SILVER RATE

\begin{tabular}{|c|c|c|c|c|c|c|}
\hline \multirow[b]{2}{*}{$\begin{array}{c}\text { Step } \\
\text { s }\end{array}$} & \multicolumn{3}{|c|}{ Gold rate } & \multicolumn{3}{|c|}{ Silver rate } \\
\hline & Actual & $\begin{array}{c}\text { predicte } \\
\mathrm{d}\end{array}$ & $\begin{array}{c}\text { Erro } \\
r\end{array}$ & $\begin{array}{c}\text { Actua } \\
1\end{array}$ & $\begin{array}{c}\text { predicte } \\
\mathrm{d}\end{array}$ & $\begin{array}{c}\text { Erro } \\
r\end{array}$ \\
\hline $\begin{array}{c}1 \\
\text { step }\end{array}$ & & 1141 & 1.55 & & 15 & $\begin{array}{c}0.23 \\
3\end{array}$ \\
\hline $\begin{array}{c}2 \\
\text { step }\end{array}$ & & 1139 & 3.55 & & 14 & $\begin{array}{c}0.76 \\
7\end{array}$ \\
\hline $\begin{array}{c}3 \\
\text { step }\end{array}$ & & 1147 & 4.45 & & 18 & $\begin{array}{c}3.23 \\
3\end{array}$ \\
\hline $\begin{array}{c}4 \\
\text { step }\end{array}$ & & 1147 & 4.45 & & 11 & $\begin{array}{c}3.76 \\
7\end{array}$ \\
\hline $\begin{array}{c}5 \\
\text { step }\end{array}$ & $\begin{array}{c}1142.5 \\
5 \text { USD }\end{array}$ & 1136 & 6.55 & $\begin{array}{l}14 . / 6 \\
7 \text { USD }\end{array}$ & 17 & $\begin{array}{c}2.23 \\
3\end{array}$ \\
\hline $\begin{array}{c}6 \\
\text { step }\end{array}$ & $\begin{array}{l}\text { (3 Feb } \\
2016)\end{array}$ & 1148 & 5.45 & Mar & 19 & $\begin{array}{c}4.23 \\
3\end{array}$ \\
\hline $\begin{array}{c}7 \\
\text { step }\end{array}$ & & 1150 & 7.45 & & 10 & $\begin{array}{c}4.76 \\
7\end{array}$ \\
\hline $\begin{array}{c}8 \\
\text { step }\end{array}$ & & 1132 & $\begin{array}{c}10.5 \\
5\end{array}$ & & 12 & $\begin{array}{c}2.76 \\
7\end{array}$ \\
\hline $\begin{array}{c}9 \\
\text { step }\end{array}$ & & 1130 & $\begin{array}{c}12.5 \\
5\end{array}$ & & 18 & $\begin{array}{c}3.23 \\
3\end{array}$ \\
\hline $\begin{array}{l}10 \\
\text { step }\end{array}$ & & 1132 & $\begin{array}{c}10.5 \\
5\end{array}$ & & 10 & $\begin{array}{c}4.76 \\
7\end{array}$ \\
\hline
\end{tabular}

(1 step $=3$ days= sampling instance)

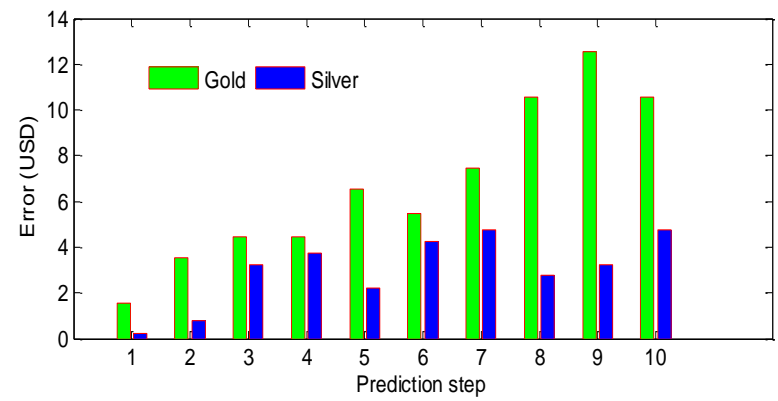

Fig. 8. Error values from 1 step to 10 step prediction

\section{Conclusion}

In this paper, B-J and ARIMA modelling techniques are used to model gold rate and silver rate. In order to improve the accuracy, the PSO based methodology is adopted to enhance the model outcome of B-J and ARIMA. From the deviation (error) between the actual data and the modelled data, it is observed that the ARIMA offers the better accuracy in gold rate and silver rate compared with the B-J approach. Later, the proposed methodology is used to design the Kalman filter to predict the gold and silver rate (10 step ahead predictions) for the considered data set. From the simulation study, it can be observed that, the proposed approach helps to achieve better prediction of the gold and silver rate with nominal error values. In future, the proposed method can be used to analyse the other related dataset and the real time gold and silver database obtained from various traders.

\section{REFERENCES}

[1] B. Li, "Research on WNN modeling for gold price forecasting based on improved artificial bee colony algorithm," Computational Intelligence and Neuroscience, vol. 2, no. 2, pp. 1-10, 2014. DOI: $10.1155 / 2014 / 870160$

[2] H. Mombeini and A. Yazdani-Chamzini, "Modeling gold price via artificial neural network," Journal of Economics, Business and Management, vol. 3, no. 7, pp. 699-703, 2015.

[3] K. S. Sujit and B. Rajesh Kumar, "Study on dynamic relationship amonggold price, oil price, exchange rate andstock market returns," International Journal of Applied Business and Economic Research, vol. 9, no. 2, pp. 145-165, 2011.

[4] S. Shafiee and E. Topal, "An overview of global gold market and gold price forecasting," Resources Policy, vol. 35, no. 3, pp. pp. 178-189, 2010. DOI: 10.1016/j.resourpol.2010.05.004

[5] S. Kumar Chandar, M. Sumathi and S. N. Sivanadam, "Forecasting gold prices based on extreme learning machine," International Journal of Computers Communications \& Control, vol. 11, no. 3, pp. 372-380, 2016. DOI: $10.15837 /$ ijccc.2016.3.2009

[6] US Gold. (1973). Daily gold and silver prices from 1968 to present [Online]. Available: http://goo.gl/YmWSYv

[7] D. M. M. A. Khan, "Forecasting of gold prices (Box Jenkins Approach)," International Journal of Emerging Technology and Advanced Engineering, vol. 3, no. 3, pp. 662-670, 2013.

[8] L. Abdullah, "ARIMA model for gold bullion coin selling prices forecasting," InternationalJournal of Advances in Applied Sciences, vol. 1, no. 4, pp.153-158, 2012. DoI: 10.11591/ijaas.v1i4.1495

[9] L. Ljung, System identification-Theory for the User. Englewood Cliffs, NJ: Prentice Hall, 1999.

[10] J. Kennedy and R. C. Eberhart, "Particle swarm optimization," In Proceedings of the IEEE International 
Conference on Neural Networks, vol. 4, pp. 1942-1948, [14] A. Rahimi, "Particle swarm optimization based adaptive 1995. DOI: $10.1109 /$ ICNN.1995.488968 kalman filters for fault diagnosis of reaction wheels,"

[11] V. Rajinikanth, N. Sri Madhava Raja and K. Latha, "Optimal multilevel image thresholding: An analysis Master dissertation, K. N. Toosi University of with PSO and BFO algorithms," Australian Journal of [15] R. Faragher, "Understanding the basis of the Kalman Basic and Applied Sciences, vol. 8, no. 9, pp. 443-454, 2014.

filter via a simple and intuitive derivation," IEEE Signal Processing Magazine, vol. 29, no. 5, pp. 128-132, 2012. DOI: $10.1109 /$ MSP.2012.2203621

[12] K. Sundaravadivu, S. Sivakumar and N. Hariprasad, "2DOF PID controller design for a class of FOPTD Models-An analysis with heuristic algorithms," Procedia Computer Science, vol. 48, pp. 90-95, 2015. DOI: $10.1016 /$ j.procs.2015.04.155

[13] Ravi Kumar Jatoth and T. Kishore Kumar, "Hybrid GAPSO based tuning of unscented kalman filterfor [17] S. Selvanathan and E. A. Selvanathan, "The effect of the bearings only tracking," International Journal of Information and Computation Technology, vol. 4, no. 3, pp. 315-328, 2014.

[16] R. K. Jatoth and T. K. Kumar, "Particle swarm optimization based tuning of extended kalman filter for manoeuvring target tracking," International Journal of Circuits, Systems and Signal Processing, vol. 3, no. 3, pp. 127-136, 2009.

price of gold on its production: A time-series analysis," Resources Policy, vol. 25, no. 4, pp. 265-275, 1999. D0I: 10.1016/S0301-4207(00)00002-7

— This article does not have any appendix. - 